\title{
TRADUCCIÓN Y RECEPCIÓN DE TEXTOS CLÁSICOS. SOBRE REFLEXIONES EN TORNO AL ARTE Y LOS ARTISTAS
}

\author{
por PILAR MARTINO ALBA \\ (Universidad Rey Juan Carlos, Madrid)
}

\begin{abstract}
Resumen
Los textos de contenido histórico-artístico conforman un amplio y variado corpus plurigenérico y multiforme que habitualmente abordan los traductores con una amplia formación humanística. De ese vasto corpus, en nuestro artículo abordamos los textos clásicos sobre reflexiones en torno al arte y los artistas, escritos por autores de expresión alemana entre 1700 y 1850 , y analizamos quiénes son sus traductores al español.
\end{abstract}

Palabras clave: traducción humanística; textos histórico-artísticos; traductores humanistas; traducción literaria; traducción especializada.

Translation and reception of classic texts. On reflections on art and artists

\begin{abstract}
Texts with historical and artistic content make up a wide and varied multi-generic and multi-form corpus that is usually dealt by translators with a broad humanistic background. From this wide corpus, our paper deals with the classic texts on reflections on art and artists written in German between 1700 and 1850 and analyses who their translators into Spanish are.
\end{abstract}

Keywords: humanistic translation; historical-artistic texts; humanistic translators; literary translation; specialized translation.

En el marco de la traducción humanística, ocupa un lugar digno de mención la traslación al español de textos clásicos sobre reflexiones en torno al arte y los artistas. La dignidad que se merecen las obras de teoría estética, tratados sobre disciplinas artísticas, ensayos y artículos de investigación de contenido histórico-artístico, estudios sobre la vida y obra de artistas plásticos o escritos sobre técnicas artísticas, constituyen un corpus de textos que, sin lugar a dudas, enriquece el polisistema cultural en español, tanto por su contribución al avance del conocimiento como por la nómina de ilustres traductores humanistas que lo abordan. A pesar de ello, este sector de la traducción especializada no goza de la atención que su importancia requeriría, tanto de los estudiosos como de los estudios de traducción. En el primero de los casos, como tema de investigación humanística, y en el segundo, como posible salida profesional en un sector económico cada vez más internacionalizado.

Entre las principales motivaciones para abordar este trabajo está, además del interés personal y profesional por los textos de contenido histórico-artístico, la lectura 
de una obra del poeta y traductor español Luis Antonio de Villena, ${ }^{1}$ publicada en 2014, Los placeres del arte, en la que presenta una cincuentena de artículos sobre reflexiones en torno al arte y los artistas, resultado de su pasión por las artes plásticas, y su afirmación de que "[...] el arte (como disciplina humanística), además de gusto y paladar, precisa sabiduría, conocimientos en torno a la propia historia del arte, pero también en torno a otras disciplinas, como historia, filosofía, literatura, etc., sin las cuales resulta difícil leer lo que vemos [...]". Esta afirmación de Villena en torno a la necesidad de una amplia formación humanística para entender el arte nos llevó, dada nuestra inclinación hacia la triple perspectiva interdisciplinar de historia del arte, filología y traducción, a buscar paralelismos en textos similares debidos a escritores de expresión alemana con el fin de indagar en la recepción a través de la traducción al español de ese tipo de textos de contenido histórico-artístico, y muy especialmente en abordar quiénes son los traductores que se embarcan en esta intermediación que enriquece la cultura meta.

Por lo que respecta a la estructura en la que hemos dividido el artículo, en la primera parte del mismo aludimos, desde el punto de vista teórico, a la amplia variedad tipológica de textos cuyo contenido se encuentra en el ámbito histórico-artístico, y citamos varios textos cuya traducción ha supuesto un hito en el mundo académico de las disciplinas directamente vinculadas con este ámbito de conocimiento, como pueda ser el caso de las siguientes obras: Vidas de pintores, escultores y arquitectos ilustres de Giorgio Vasari; los Cuadernos de notas sobre arte, literatura, ciencia y filosofía de Leonardo da Vinci, o De la medida de las partes del cuerpo humano, de Alberto Durero, entre otras.

Precisamente esta última obra, publicada en 1528, enlaza la primera con la segunda parte del artículo, en la que focalizamos la atención en un marco espacial y cronológico concreto. En este cronotopo hemos fijado la atención en la traducción y recepción de textos clásicos sobre reflexiones en torno al arte y los artistas, escritos por autores de expresión alemana entre 1700 y 1850. La elección de este amplio período, que abarca varios grandes movimientos creativos, permite ahondar en la producción intelectual de una época en la que el afán por comprender y explicar la historia del arte produjo textos de gran profundidad. Los autores trataban de reflexionar sobre el equilibrio que la creación artística, por un lado, y la contemplación de obras por el público receptor, por otro, tenía entre razón y sensibilidad, e influyeron en el decurso posterior de ideas y gustos europeos. A título de ejemplo, algunos de los autores que forman parte de este corpus son Bodmer, Hagedorn, Winckelmann, Lessing, Lavater, Herder, Goethe, Novalis, Burckhardt o Heine.

Los parámetros cronoespaciales que nos hemos marcado para este estudio, tal y como hemos mencionado, han sido un siglo y medio en los territorios de cultura y expresión alemanas, mientras que el corpus de autores y textos abarca una cincuentena de nombres y títulos. ${ }^{2}$ Tan amplio marco espacial, temporal y nominal, se

1 En calidad de traductor, también ha vertido al español textos de artistas plásticos, concretamente la obra poética de Miguel Ángel BUONARROTI (1475-1564), Sonetos completos, Madrid 1987.

2 De ella, ofrecemos aquí tan solo, por razones de espacio, una pequeña muestra. El resto de los trabajos irá apareciendo en sucesivas publicaciones, así como el estudio realizado de la traducción y 
reduce tan solo a diez traductores especializados en este amplio abanico de textos que están a medio camino entre la traducción de filosofía, estética, historia del arte y literatura. ${ }^{3}$ Quizá la exigencia de una amplia y profunda formación humanística en este campo de la traducción especializada ha provocado que aún sean muchos los textos que esperan ser trasladados a nuestro polisistema cultural.

Los perfiles de estos traductores y la recepción de los textos constituyen la última parte del artículo, que concluimos con unas reflexiones finales sobre las razones que motivan el que textos clásicos de alto valor tanto conceptual como literario no tengan una mayor cabida en el mundo académico de la traducción.

La alusión a textos histórico-artísticos nos induce, en ocasiones, a pensar en un mismo tipo de texto desde el punto de vista formal, pero con gran variedad de contenido. Nada más alejado de la realidad. ${ }^{4}$ Hemos mencionado al inicio, a título de ejemplo, tres textos clásicos numerosas veces traducidos y a varias lenguas. Ninguno de ellos es semejante a los otros dos. Por un lado, tenemos una obra formada por pequeños fragmentos biográficos de los más diversos artistas italianos, escrita por el historiador del arte y arquitecto Giorgio Vasari (1511-1574). En segundo lugar, tenemos una obra de otro artista italiano, pero en esta ocasión es un pintor e inventor quien la escribe, Leonardo da Vinci (1452-1519). Sin embargo, no versa sobre obra propia, sino sobre las reflexiones que en el artista provocan diferentes disciplinas. Leonardo da Vinci tenía por costumbre anotar en cuadernos estas ideas que quizá más adelante pudieran servirle de inspiración. Por último, estamos ante una obra escrita también por un artista, pero del Renacimiento alemán, Alberto Durero (14711528), y no se trata ni de una obra biográfica, ni autobiográfica, ni de anotaciones como en el caso anterior, sino de un ensayo fundamental para la creación artística de acuerdo a los presupuestos renacentistas, a saber: de la medida del cuerpo humano. Estas ideas de medición y proporción entre las diferentes partes del cuerpo supondrían un hito en el mundo de la creación artística centroeuropea. La obra dureriana: Vier Bücher von menschlicher Proportion o Cuatro libros sobre la proporción del cuerpo humano, se publicó por primera vez en 1528. Unos años después, la obra

recepción de este tipo de textos en el período comprendido aproximadamente entre 1850 y 1950, y otro más que abarca desde esta última fecha hasta la actualidad.

3 En el artículo ofrecemos los perfiles de cinco de los traductores, de entre la decena que han abordado la cincuentena de autores y obras seleccionadas. Estos cinco consideramos que son los más relevantes en textos de teoría estética, sobre todo, pero también de otros de contenido histórico-artístico, cuyo proceso traductor exige una formación humanística excepcional. Son todos los que están, aunque no estén todos los que son. Los perfiles de los diferentes traductores irán saliendo a la luz en los otros dos estudios mencionados.

4 Véanse al respecto algunos de nuestros anteriores trabajos sobre características y dificultades de los textos de contenido histórico-artístico, así como sobre la tipología textual: Pilar MARTINO ALBA, idem, La autobiografía artística como problema de traducción, Alicante 2016; idem, "La formación humanística ante la traducción especializada”, in: Antonio Bueno y Miguel Ángel Vega (eds.), Traducción y Humanismo, Bruselas: Éditions du Hazard, 2013, pp. 297-312; idem, "Exposiciones internacionales de arte: estudio traductológico", Hieronymus Complutensis 12, 2005/2006, pp. 35-49; idem, "La traducción de textos histórico-artísticos", Philologia Hispalensis XIX/2, 2005, pp. 149-163 
fue traducida al latín. ${ }^{5}$ De esta obra se publicó en México una edición en español en 1987, en la traducción del latín al español de Jesús Yhmoff Cabrera. Así, pues, se trata de un texto fundamental para el avance del conocimiento en historia del arte $\mathrm{y}$, a pesar de ello, los historiadores cuya lengua materna es el español no han podido leer la obra en esta lengua, aunque sí en latín, hasta algo más de cuatrocientos cincuenta años después de su publicación. Este hecho induce, sin lugar a dudas, a reflexionar sobre el papel del traductor como mediador lingüístico y cultural y las consecuencias de su ausencia en el avance del conocimiento de determinadas disciplinas en diferentes culturas.

Teniendo en cuenta la amplitud y variedad de textos de contenido histórico-artístico, conviene retrotraerse a algunos de los teóricos considerados por la traductología en Occidente como pioneros en abordar la reflexión en torno a tipos y clases de textos. De esa reflexión, hemos focalizado la atención especialmente en lo que los estudiosos de la tipología textual dicen de los textos literarios, dados nuestro objeto de interés y el marcado componente estético en la redacción de estos textos histórico-artísticos. A propósito del crecimiento exponencial que se extendió en los albores de la reflexión teórica en torno a la traducción, recordamos al respecto las palabras de Vega Cernuda: ${ }^{6}$

Fue la consideración de la traducción desde el punto de vista de la comunicación la que dio lugar a la teoría de la tipología textual de Reiss, ${ }^{7}$ que postulaba para cada uno de los tipos de textos una metodología diversa [... Y, por encima de todo, a la hora de establecer la estrategia de traducción, se debía tener en cuenta la voluntad del mandante que hacia el encargo.

En relación con los eruditos que se han ocupado de la tipología textual, no pretendemos hacer un repaso de sus presupuestos teóricos al respecto, dado que el objeto de nuestro trabajo está focalizado en los traductores, en destacar la personalidad y labor de los actores del proceso traductor de textos histórico-artísticos. A pesar de ello, sí consideramos pertinente mencionar a determinados teóricos que abordaron la tipología textual, como es el caso de Reiss y otros muchos antes que ella, con el fin de poder comprobar si los textos objeto de nuestro interés en este artículo han sido tenidos en cuenta por los teóricos del lenguaje y de la tipología

5 Hay un interesante artículo de Miguel Ángel ZALAMA RODRÍGUEZ sobre un ejemplar de la edición en latín custodiado en la Biblioteca de Santa Cruz, en Valladolid. El autor ofrece datos sobre anotaciones hechas en dicho ejemplar que demuestran que fue utilizado y traducido por sus sucesivos propietarios. Véase: Miguel Ángel ZALAMA RODRÍGUEZ “Un ejemplar de Cuatro libros sobre las proporciones humanas de Durero en la Biblioteca de Santa Cruz de Valladolid", Boletín del Seminario de Estudios de Arte y Arqueología 68, 2002, pp. 191-198.

6 Miguel Ángel VEGA CERNUDA, "Una mirada retrospectiva y escéptica a la teoría de la traducción”, Hieronymus Complutensis 9/10, Madrid, 2002/2003, pp. 63-76. Aquí p. 69.

7 Katharina REISS, “Type, Kind and Individuality of Text: Decision Making in Translation”, Poetics Today 2/4 (=Translation Theory and Intercultural Relations. Summer-Autumn 1981), pp. 121-131. Sus primeros textos teóricos sobre tipología textual tuvieron lugar en 1971 y, con posterioridad, sus reflexiones, precisamente por poner el foco en el mandante y en el destinario, quedaron incorporadas a la teoría funcional de la traducción que acuñaron Vermeer y Reiss. 
textual. Especial interés nos merece el esquema tripartito de las funciones del lenguaje que propugnara Karl Bühler, ${ }^{8}$ pues los términos que utiliza para describir dichas funciones, a saber: Ausdruck (expresión), Apell (llamada o apelación) y Darstellung (representación) son términos también propios de las artes plásticas. ${ }^{9}$ Por otro lado, el esquema que proponía Roman Jakobson, basado en términos lingüísticos y funcionales, trataba también de servir de marco formal al concepto de literaturnost o literariedad. ${ }^{10}$ Según la taxonomía de Katharina Reiss y la distinción que hace entre tipo, clase y campo, los textos de contenido histórico-artístico formarían el campo textual, mientras que los referidos a las reflexiones en torno al arte y los artistas compondrían clases de texto, y el corpus de tipos de texto estaría compuesto por la amplia variedad de ellos que tocan diferentes aspectos del arte y sobre los artistas, y que cumplen con los tres aspectos semióticos básicos del texto: representación del mundo, función comunicativa, estructura propia. ${ }^{11} \mathrm{La}$ importancia que esta última concede al conocimiento de la teoría sobre los tipos de texto y a la práctica de sus regularidades y convenciones entre los traductores está directamente relacionada con las competencias del traductor, especialmente la competencia cultural en el uso del lenguaje, pero incide en la dificultad que supone para el traductor cuando se encuentra ante tipos de texto complejos, entre los que cabría incluir a buena parte de los textos histórico-artísticos. ${ }^{12}$ Ninguno de estos autores menciona en la clasificación tipológica específicamente los textos de contenido histórico-artístico.

Los tres textos renacentistas anteriormente citados, diferentes en lo formal y en el contenido, supusieron un importante paso adelante en la evolución de la concepción del arte y del papel del artista en la sociedad. Pero son también otros muchos los que forman parte de un corpus cognoscitivo que ha contribuido a modernizar la cultura de la sociedad en la que se ha publicado. De esas sociedades, como ya hemos mencionado, nos hemos fijado en las de cultura y lengua alemanas a partir del siglo XVIII, pues con el nacimiento y desarrollo de la Ilustración, el Clasicismo y el Romanticismo alemanes, los pensadores de expresión alemana se plantean numerosas preguntas en torno al papel del arte y los artistas. Legarán sus reflexiones a la posteridad en textos cuya tipología formal abarca un amplio abanico de posibilidades.

El motivo sobre el que han construido su texto ha dado lugar, en unos casos -los menos-, a una biografía, a un ensayo sobre crítica de arte, a la descripción de una obra concreta inserta en una epístola o también a la recreación de una supuesta

8 Karl BÜHLER, Sprachtheorie. Die Darstellungsfunktion der Sprache, Jena 1934. Hay una traducción al español, por el filósofo español Julián Marías. Julián MARÍAS, “Teoría del lenguaje”, Revista de Occidente, Madrid 1950.

9 Véase Pilar MARTINO, La autobiografía artística como problema de traducción, Alicante 2016, p. 132.

10 Ibidem, p. 133.

11 Véase Katharina REISS y Hans J. VERMEER, Fundamentos para una teoría funcional de la traducción, Torrejón de Ardoz (Madrid) 1996, p. 154.

12 Véase Pilar MARTINO, La autobiografía, p. 135. 
correspondencia, novelando una relación epistolar basada en artistas y géneros pictóricos concretos: a un poema dedicado a un artista o a una obra, a una novela de formación o Bildungsroman -tomando como modelo a un artista- a un texto filosófico sobre estética, a una obra enmarcada en la literatura odepórica, en la que las descripciones viajeras detallan con precisión arte y paisaje, etc. La casuística es plurigenérica y multiforme. Con el fin de fijar a través de ejemplos concretos esta tipología textual, apuntar algunas de sus características y dificultades para la traducción y tratar de averiguar las razones de su minoritaria recepción, en el siguiente epígrafe aportamos los datos sobre los autores y obras seleccionados, así como las fechas de publicación en lengua original (alemán) y, en su caso, la fecha de traducción al español y quién la hizo.

Al tratarse de un amplio período cronológico, culturalmente glorioso en la creación literaria en lengua alemana, y muy especialmente estudiado por los germanistas españoles,${ }^{13}$ pensamos que, al menos a priori, debería ofrecer un corpus traductográfico al español mayor que el de la producción literaria de otras épocas y que, consecuentemente, sería lo suficientemente representativo como para permitirnos establecer algunas ideas generales válidas para la traslación de estos textos y su recepción en la cultura de lengua española.

\section{Selección de textos clásicos de contenido histórico-artístico en lengua alemana (1725-1875) y su recepción en el polisistema cultural español}

Como ya hemos mencionado anteriormente, ofrecemos aquí solamente una pequeña muestra del total de obras estudiadas.$^{14}$ Los autores de la decena de títulos que figuran en la siguiente relación son grandes firmas de la historia de la literatura en lengua alemana. Dichas obras son fruto de la pausada reflexión ante el efecto que en el observador y lector de imágenes causa la contemplación de una obra de arte, el reconocimiento de un estilo artístico o de un movimiento cultural, los datos aportados en la biografía de un artista, la novedad de un género pictórico determinado o los relatos de viaje de un artista. Algunos de estos textos requieren una cierta familiaridad con la filosofía y la estética; otros, con la historia de la cultura y sus manifestaciones artísticas a través de las artes plásticas o literarias; en otros casos el lector comprenderá mejor el texto si previamente conoce las imágenes, artísticas o paisajísticas, que se describen, etc. Y, en cualquier caso, todos ellos se caracterizan por una fuerte carga terminológica y conceptual, así como por una abundante presencia de referentes culturales, como veremos a continuación a través de algunos fragmentos de los textos meta. La relación de textos seleccionados es la siguiente:

13 No podemos obviar que en este período vive el gran vate de las letras alemanas, Goethe, quien también, en calidad de asesor del duque de Weimar, estaba encargado de adquirir obras de arte para él y, asimismo, escribió textos de contenido histórico-artístico.

14 Las búsquedas se han realizado tanto en la base de datos del Index Translationum de la Unesco como en el catálogo digital de la Biblioteca Nacional de España. 
a. Johann Jakob BODMER (1698-1783): Discourse der Malern, Berlin\&Stuttgart 1721 [trad. de Miguel Ángel Vega: "Discurso de los pintores", en Textos clásicos de teoría de la traducción, Madrid: Cátedra, 1994]. El valor de esta obra de Vega Cernuda, en la que se inserta un fragmento del texto de Bodmer, reside no solo en la aportación que supone la traducción de textos clásicos de teoría de la traducción, muchos de ellos vertidos por primera vez al español, sino también, y sobre todo, en el magnífico estudio introductorio crítico y texto teórico fundamental en esta disciplina académica.

En el fragmento de Bodmer aquí seleccionado, en el que hay muchas semejanzas con el ciceroniano De Oratore, el autor alemán afirma, a propósito del arte como imitación de la naturaleza, que tanto los escritores como los pintores y los grabadores tienen en la naturaleza a su mejor maestra; sin embargo, al representarla, no se trata de copiar sin más el objeto a describir, sino de reflexionar sobre él. En este sentido, Bodmer concede una mayor perfección al escritor que al artista plástico, pues el primero puede jugar con la riqueza semántica de las palabras para describir las cualidades de un objeto o las pasiones del personaje representado. A pesar de ello, dice que el receptor capta con una mayor impresión las imágenes que las palabras, porque sus obras ejercen una superior influencia sobre la imaginación que el texto escrito o la narración oral. Así, pues, para poder captar mejor la atención del espectador-lector:

[...] no es suficiente para aquel que quiera hablar correctamente, el conocer las palabras y los conceptos precisos que los acompañan; tiene, además, que dominar el arte de emplear las palabras en su orden correcto [...] Aquel que domina el arte de emplear las palabras en su orden correcto es quien habla bien [...] lo mismo que no se puede llamar arquitecto a aquel que, teniendo a su disposición todos los materiales para un palacio, no domina el arte de disponer de forma adecuada las piedras y la madera ya cortada $[\ldots] .{ }^{15}$

b. Ch. Ludwig von HAGEDORN (1712-1780): Betrachtungen über die Mahlerey, Leipzig 1762. De esta obra no existe traducción al español. La biblioteca del Museo del Prado conserva una edición facsímil, en francés, de la obra Lettre à un amateur de la peinture avec des éclaircissements historiques sur un cabinet et les auteurs des tableux qui le composent: ouvrage entremêlé de disgressions sur la vie de plusieurs peintres modernes, Dresden: G. C. Walther, 1755, 368 págs., escrito junto con Franz Christoph Janneck.

c. Johann Joachim WINCKELMANN (1717-1768): Gedanken über die Nachahmung der griechischen Werke in der Malerei und Bildhauerei, Dresden 1755 [trad. de Vicente Jarque Soriano: "Reflexiones sobre la imitación del arte griego en la pintura y escultura", en Belleza y verdad. Sobre la estética entre la Ilustración y el Romanticismo, Barcelona: Alba 1999, pp.79-123]. En este texto, las referencias de Winckelmann a la mitología griega y romana, y a las obras de arte de la Antigüedad

15 Citado según Miguel Ángel VEGA: Textos clásicos de teoría de la traducción, Madrid 1994, p.165. 
clásica son constantes. En unas ocasiones son alusiones explícitas, mientras que en otras están apenas sugeridas, de manera que exigen del traductor un estudio y/o conocimiento previo de la materia para poder comprender en su justa medida el sentido del texto y sus aspectos connotativos.

El buen gusto, que se extiende más y más por el mundo, comenzó a formarse por primera vez bajo el cielo griego [...] El único camino que nos queda a nosotros para llegar a ser grandes [...] es el de la imitación de los Antiguos [...] Es preciso haber llegado a conocerlos como se conoce al amigo para encontrar al Laocoonte tan inimitable como a Homero. Desde tal estrecha familiaridad se juzgará como Nicómaco la Helena de Zeuxis [...]. ${ }^{16}$

d. Gotthold Ephraim LESSING (1729-1781): Laokoon oder Über die Grenzen der Malerei und Poesie, Berlin 1766 [trad. de: a) Javier Merino: Laocoonte o Sobre los límites de la pintura y de la poesía: seguidas de las cartas sobre la literatura moderna y sobre el arte antiguo, Buenos Aires 1946; b) Enrique Palau: Laocoonte o sobre los límites de la pintura y de la poesía, Barcelona 1957, y c) Eustaquio Barjau: Laocoonte, Madrid 1977, y Ed. Tecnos, 1990]. El texto de Lessing incluye numerosas citas a textos de otros estudiosos, lo que demuestra el conocimiento del autor alemán sobre la literatura en torno a la historia y la crítica de arte. En ocasiones rebate a los autores que cita; en otras argumenta a su favor, y en otras más, coincide y profundiza en esas afirmaciones. Ello obliga al traductor a la inclusión de un gran aparato crítico y a la investigación y consulta bibliográfica extensa en el proceso traductor.

De entre los conocedores del mundo antiguo hay quienes opinan que, aunque el grupo del Laocoonte es debido a artistas griegos, pertenece con todo a la época imperial, porque creen que el modelo de este conjunto escultórico fue el personaje de Virgilio. De entre los eruditos antiguos, que son de esta opinión citaré sólo a Bartolomé Marliani, de entre los modernos a Montfaucon [....$^{17}$

e. Johann Gottfried HERDER (1744-1803): Plastik: einige Wahrnehmungen über Form und Gestalt aus Pigmalions bildendem Traum, Riga/Leipzig 1778 [trad. de Vicente Jarque Soriano: Escultura: algunas observaciones sobre la forma y la figura a partir del sueño plástico de Pigmalion, Valencia 2006/2011].

16 Citado según la traducción de Vicente JARQUE SORIANO: Belleza y verdad. Sobre la estética entre la Ilustración y el Romanticismo, Barcelona 1999, pp. 79-80. Al igual que en el caso que mencionamos en la cita anterior, también este autor y traductor aporta un estudio introductorio fundamental ("La importancia de los estudios estéticos en el siglo XVIII") para la comprensión del contexto en el que se insertan los textos que traduce.

17 Citado según la traducción de Eustaquio BARJAU: Laocoonte. Gotthold Ephraim Lessing, Madrid 1990, p. 39. De nuevo estamos ante la traducción de una obra fundamental para la historiografía artística y que incluye, como en los dos casos anteriores, un profundo estudio introductorio y notas a pie de página. 
f. Johann Wolfgang von GOETHE (1749-1832): Nach Falconet und über Falconet, Berlin, 1775 [trad. de Javier Arnaldo: "Según Falconet y sobre Falconet", en Johann Wolfgang von Goethe. Paisajes, Madrid 2008]. Este traductor, autor al igual que los anteriores, y comisario de la exposición sobre Goethe que tuvo lugar en el Círculo de Bellas Artes, incluye en el catálogo un artículo titulado "Goethe: el paisaje como imagen" (pp. 15-32), en el que cita el texto goetheano sobre Falconet, ${ }^{18}$ además de situar al lector en el contexto propicio para comprender las relaciones del autor alemán con las artes.

El artista halla la concordancia con mucha más fuerza en los objetos de la naturaleza que en el mármol que los representa.

[...] Tampoco busca el artista el propósito en la materia con la que trabaja, sino que sabe verlo en la naturaleza, lo encuentra igual de bien en la escayola que en el mármol, puesto que es falso que el yeso de un mármol armonioso no sea asimismo armonioso; si no, sólo podrían hacerse vaciados sin sentimiento; el sentimiento es concordancia y viceversa $[\ldots]$.

g. Caroline von HUMBOLDT (1766-1829): “Rafaels Gemälde in Spanien”, Jena 1809 [el texto no se ha traducido, aunque Miguel Ángel Vega menciona la correspondencia de esta autora con los eruditos alemanes en el estudio introductorio al Diario de viaje a España 1799-1800 de Wilhelm von Humboldt, Madrid: Editorial Cátedra, col. Letras universales, 1998].

h. Ludwig TIECK (1773-1853): Das Jüngste Gericht von Michelangelo, Berlín, 1799 [trad. de Javier Arnaldo: "El juicio final de Miguel Ángel”, en Fragmentos para una teoría romántica del arte, Madrid, Editorial Tecnos, 1987/1994].

i. Carl Gustav CARUS (1789-1869): Neun Briefe über Landschafstmalerei, Dresden, 1831 [trad. de José Luis Arántegui: Cartas y anotaciones sobre la pintura de paisaje, Madrid 1992]. En este caso, estamos ante una obra cuya introducción ha sido realizada por el autor y traductor anteriormente citado, Javier Arnaldo. Sin embargo, por la ficha traductográfica que aportaremos un poco más adelante sobre el traductor Arántegui, también en esta ocasión estamos ante un autor y traductor, cuya producción bibliográfica pone de manifiesto una trayectoria fuertemente ligada a la cultura de expresión alemana, especialmente con los clásicos, aunque no excluye a otros autores, de la literatura en lengua alemana. El fragmento siguiente exige un conocimiento de los conceptos -como decía Bodmer en el texto citado sobre el Discurso de los pintores-, además de las palabras, su significado y su orden.

[...] sólo llego a experimentar el completo y auténtico placer poético cuando se aúnan ante una obra de arte las vivas exigencias de mi sensibilidad con la clara comprensión de su perfección interna, y con la percepción de un propósito puro en el

18 Citado según la traducción de Javier Arnaldo, p. 21. 
artista: un placer que entonces, fundado en la belleza, la verdad y la justicia, ya no disminuye por más que se repita la contemplación de la obra de arte clásica [...]. ${ }^{19}$

j. Heinrich HEINE (1797-1856): Reisebilder, Hamburg: Hoffmann\&Campe, 1826, 1827, 1830 [trad. de: a) Lorenzo González Agejas, Madrid 1889; b) Isabel García Adánez, Madrid 2003; c) Miguel Ángel Vega Cernuda, Madrid: Cátedra, 2014].

Así, pues, estamos ante autores literarios que escriben sobre arte e inspirados por las disciplinas artísticas y su efecto en el espectador. La relación entre pintura y poesía se remonta a la Antigüedad clásica. Desde que Horacio, en los versos 361 a 365 de su Arte poética, argumentara las similitudes entre ambas artes desde el punto de vista del lector o espectador final:

"Cual la pintura, tal la poesía. Habrá una que te atraiga más si más te aproximas, otra, si te retiras más lejos; ésta prefiere la penumbra, aquélla requiere ser vista a plena luz y no teme el juicio sagaz del juez; ésta te agradó una sola vez, aquélla te gustará vuelta a mirar diez veces./[...].", ${ }^{20}$

la historia de la literatura y la del arte no han dejado de analizar este emparejamiento desde diferentes perspectivas: desde la inspiración e imitación de la naturaleza, la écfrasis o interpretación de una imagen a través de la palabra, pasando por la percepción del mundo a través del llamado ojo cósmico o abordándolo desde la traducción intersemiótica. En otras ocasiones, no se ha ido más allá de la pura mención inicial del verso horaciano Ut pictura poesis para buscar las referencias al arte en general y a la pintura en particular por parte de autores literarios, o bien a las obras escritas por los artistas plásticos, bien fuesen literarias, tratadísticas o ensayísticas.

Los eruditos de expresión alemana, ya sean alemanes, suizos o austriacos, cuya fascinación por la Antigüedad clásica y por las ideas estéticas ha dado al mundo del arte grandes arqueólogos, historiadores del arte y pensadores sobre la creación artística desde Durero en adelante, tales como Winckelmann (Historia del arte de la Antigüedad), Jacob Burckhardt (La cultura del Renacimiento en Italia), Heinrich Wölfflin (Reflexiones sobre la historia del arte), Erwin Panofsky (Estudios sobre iconología), Carl Justi (Velázquez y su siglo), Arnold Hauser (Historia social de la literatura y del arte), Rudolf Wittkower (La escultura: procesos y principios), Ernst Gombrich (Historia del Arte, Arte e ilusión, Norma y forma, El legado de Apeles, entre otras muchas obras) y una larga nómina de autores que ha gozado de desigual fortuna translatoria a nuestra lengua. Los que acabamos de mencionar empezaron a entrar en el panorama editorial español a partir de los años setenta del siglo XX -a excepción de Winckelmann, quien ya había sido traducido con anterioridad- convirtiéndose entre los interesados en la historia del arte en textos no solo

19 Citamos por la traducción de José Luis ARÁNTEGUI, p. 63.

20 Citamos por la traducción de Juan GIL: Horacio. Arte poética [edición bilingüe, introducción y notas de Juan Gil], Madrid 2010. 
de obligada lectura sino también leídos con fruición por su novedad en la bibliografía sobre temas histórico-artísticos en español. Sin embargo, otros muchos textos de indudable interés para este sector académico fueron quedando en el ostracismo que provoca la inexistencia de mediación lingüística entre dos culturas.

$\mathrm{El}$ hecho de que, de la cincuentena de autores y obras seleccionadas para nuestro estudio, la mayoría de ellas no haya sido traducida al español, no significa que en el polisistema cultural español no existiese conocimiento de esas obras, bien fuese directamente o bien a través de la traducción al francés o al italiano de algunas de ellas, como demuestra la traducción de la obra de Winckelmann por el que fuera académico de Bellas Artes Diego Antonio Rejón de Silva ${ }^{21}$ en el siglo XVIII, o que no hubiese interés por la historiografía artística. Ya en siglos anteriores nuestros tratadistas habían producido interesantísimos y documentados ensayos y textos críticos, ${ }^{22}$ en el campo de esta disciplina, obras que, lamentablemente, sufrieron un ostracismo equivalente hasta que estudiosos extranjeros interesados en la historiografía artística española descubrieron su existencia. ${ }^{23}$ A título de ejemplo, cabría mencionar a Vicente Carducho (Diálogo de la pintura), Francisco Pacheco (Arte de la Pintura, su antigüedad y grandezas) o Jusepe Martínez (Discursos practicables del nobilísimo arte de la pintura) en el siglo XVII, Antonio Palomino (El Museo Pictórico y Escala Óptica), Antonio Ponz (Viaje de España y Viaje fuera de Espa$\tilde{n} a$ ) o Gregorio de Mayans y Siscar (Arte de pintar) en el siglo XVIII; Juan Agustín Ceán Bermúdez (Diccionario histórico de los más ilustres profesores de las Bellas Artes en España), a caballo entre los siglos XVIII y XIX; Giner de los Ríos (Estudios sobre las artes industriales), en el siglo XIX, ${ }^{24}$ etc.

Volviendo a nuestra primera selección a partir de la cual hemos extraído diez obras, es perceptible que entre los textos sobre teoría artística, ideas estéticas o crítica de arte, escritos por autores de expresión alemana, no es frecuente encontrar traducidos los que podríamos llamar textos menores -no por su contenido, sino por su longitud-, a no ser para monografías sobre un determinado autor. Este es el caso, por ejemplo, de las traducciones llevadas a cabo por Vicente Jarque Soriano para la obra Belleza y verdad. Sobre la estética entre la Ilustración y el Romanticismo; o por Javier Arnaldo para la exposición sobre Johann Wolfgang von Goethe. Paisajes o bien en Fragmentos para una teoría romántica del arte, obra para la que este autor tradujo textos de Goethe, Hegel, Novalis, Ludwig Tieck o Heinrich von

${ }^{21}$ Gracias a este académico se enriqueció la historiografía artística en España. Entre otras obras, también tradujo y publicó en un mismo volumen El tratado de la pintura por Leonardo da Vinci $y$ los tres libros que sobre el mismo arte escribió León Bautista Alberti, Madrid 1784.

22 La puesta al día del estado de la cuestión en torno a El Greco en 2014 con motivo del IV centenario de su fallecimiento en Toledo ha sacado a la luz sus opiniones sobre obras, artistas y estilos.

23 Véase al respecto la obra de Karin HELLWIG: La literatura artística española del siglo XVII [trad. de Jesús Espino Nuño, precisamente otro de los traductores especializados en textos de contenido histórico-artístico], Madrid 1999, publicada en lengua alemana en Frankfurt tan solo tres años antes de la traducción al español (título original: Die spanische Kunstliteratur im 17. Jahrhundert).

24 Véanse VVAA, Historiografía artística española de los siglos XIX y XX, Madrid 1995, 470 págs. y Gonzalo BORRÁS: Historia del arte y Patrimonio Cultural: una revisión crítica, Zaragoza 2012, 125 págs. 
Kleist; o también en el caso de Miguel Ángel Vega, quien para su Textos clásicos de teoría de la traducción vertió fragmentos que versaban tanto sobre teoría translativa como sobre la estética del texto e incluso, en una especie de ut pictura poesis, sobre la obra de artes plásticas equiparada con la obra de arte literario.

En la traducción de textos de contenido histórico-artístico se prefiere la traducción de obras y ensayos de una cierta longitud antes que artículos o conferencias publicados en las numerosas revistas de arte y literatura en lengua alemana. Incluso algunas de las llamadas novelas de artistas o Künstlerromane, como es el caso de Maler Nolten, de Eduard Mörike (Stuttgart 1832), en las que el argumento gira en torno a un artista, no han gozado, hasta ahora, de gran interés editorial. De hecho, en el caso de autores literarios de una fortuna editorial difícilmente parangonable, como es el caso de Rainer Maria Rilke, las obras ensayísticas sobre temas histórico-artísticos, aunque hayan supuesto un hito en la historiografía artística, ${ }^{25}$ quedan relegadas a un segundo puesto en el interés de los lectores. Por el contrario, la literatura de viajes narrada por artistas sí cuenta con adeptos en el mundo histórico-artístico, dado su valor como fuente de primera mano en la información de lo descrito.

\section{Perfiles traductores}

A continuación, presentamos unas brevísimas pinceladas biográficas en las que destacamos los perfiles traductográficos de cinco de los traductores que han abordado los textos que hemos seleccionado en nuestro estudio:

a. Vicente Jarque Soriano. Doctor en Filosofía, especialista en Estética, y traductor. Entre las obras traducidas del alemán, se encuentran Walter Benjamin: historia de una amistad, de Gershom Scholem, Barcelona: Península, 1987, con varias reediciones, la más reciente de ellas en 2014, traducida al español a cuatro manos con J. F. Yvars con quien ha traducido varias obras; El concepto de crítica de arte en el romanticismo alemán, de Walter Benjamin, Barcelona: Península, 1988; Escultura: algunas observaciones sobre la forma y la figura a partir del sueño plástico de Pigmalion, de Johann Gottfried Herder, Valencia 2006 y 2011; Estética sin territorio, de Siegfried Krakauer, Murcia: Col. de Arquitectos, 2006; Imágenes de época: sociología y estética de la pintura moderna, de Arnold Gehlen, Barcelona: Península, 1994. Asimismo, Jarque ha traducido capítulos de libros en los que han participado autores bien de expresión alemana o inglesa, lengua de la que también es traductor. Tal sería el caso de la obra coordinada por Raúl Rodríguez Ferrándiz: La polémica sobre la cultura de masas en el periodo de entreguerras: una antología crítica, en la que Jarque es el traductor de los textos de Siegfried Krakauer, J. B. Priestley, Virginia Woolf, R. G. Collingwood y Theodor W. Adorno, Valencia: Pub. Univ. de Valencia, 2012. En calidad de autor ha publicado Imagen y metáfora: la estética

25 Obras como Worpswede, la monografía sobre cinco de los pintores que convivían en esta colonia de artistas del norte de Alemania, o incluso las Cartas a Rodin o Cartas a Cézanne, en las que el autor utiliza un género, el epistolar, mediante el cual el lector se puede sentir más cerca de lo expresado en el texto, no han tenido, ni de lejos, la gran cantidad de reediciones de otras muchas de sus obras. 
de Walter Benjamin, Cuenca: UCLM, 1992; Experiencias de estética y ensayos de crítica, Cuenca: UCLM 2002, entre otras muchas obras.

b. Eustaquio Barjau, ${ }^{26}$ Doctor en Filosofía y catedrático de Filología alemana. Prolífico autor y traductor, en posesión de varios galardones, entre ellos el Premio Nacional a la Obra de un Traductor, en 2003, y la Gran Cruz del Mérito de la República Federal de Alemania. Es traductor, entre otros, de Peter Handke, Max Frisch, E. T. A. Hoffmann, Novalis, Rainer Maria Rilke y Günter Grass. Su labor translativa se ha centrado, sobre todo, en obras literarias, pero su condición de filósofo le ha hecho abordar también textos de Martin Heidegger, tales como Conferencias y artículos, publicado por Ediciones del Serbal en 1994 y 2001 o La pregunta por la técnica, Ediciones Folio, 2007. De su vastísima obra traductográfica, nos ha interesado especialmente su traducción al español del ensayo de crítica de arte de Gotthold Ephraim Lessing: Laocoonte, publicado por la Editora Nacional en 1978 y Tecnos en 1990 este texto lessigniano creó en su momento una ácida polémica e inauguró en la cultura alemana una nueva forma de abordar la visión estética y la crítica artística. La obra fue traducida por primera vez al español en 1957 por Enrique Palau, y tanto una como otra traducción han tenido varias reediciones, algunas muy recientes, lo que da idea del interés de la obra en el polisistema cultural español.

c. Javier Arnaldo. Doctor en Historia del Arte y traductor. Su relación con el mundo histórico-artístico de expresión alemana se remonta a su tesis doctoral (1989) sobre el Concepto de estilo en el romanticismo alemán. Como autor y traductor pronto publicó varias obras relacionadas, asimismo, con la cultura alemana: Estilo y naturaleza: la obra de arte en el romanticismo alemán, Madrid 1990, y Fragmentos para una teoría romántica del arte, Madrid 1987, en las que traduce textos de Novalis, los hermanos Schlegel o Hölderlin, entre otros. Es autor de numerosos artículos sobre temas relacionados con la cultura alemana, entre ellos, a título de ejemplo: "Las páginas de Dilthey sobre Novalis", Revista de Occidente 105 (1990), pp. 45-58; "La pregunta por la expresión en el estilo: Gombrich y Wölfflin”, Anuario del Dpto. de Historia del Arte 4, 1992, pp. 341-350; “Ópera, drama y cosmorama: Wagner y la cualidad panóptica del arte total", La Balsa de la Medusa 53-54, 2000, pp. 19-40; "La Viena de la Secession”, Descubrir el arte 92, 2006, pp. 36-41. Además de ello, ha comisariado exposiciones sobre temas histórico-artísticos relacionados con la cultura alemana, tales como: "Johann Wolfgang Goethe: Paisajes”, que se celebró entre enero de 2008 y octubre de 2009, en primer lugar, en el Círculo de Bellas Artes en Madrid y posteriormente en la Klassik Stiftung de Weimar; “¡1914! La vanguardia y la guerra”, celebrada conjuntamente en el Museo Thyssen-Bornemisza y en la Fundación Caja Madrid (2008-09) o Die Brücke. El nacimiento del expresionismo alemán, que tuvo lugar en estas mismas instituciones en Madrid en el año 2005 y a continuación en Barcelona y en Berlín.

26 Para la ficha biográfica de E. Barjau véase: Juan Antonio ALBALADEJO, Eustaquio Barjau [on-line]. Alicante 2012. HISTRAD, Biografías de traductores, [consultado el 27 de diciembre de 2018]. Accesible de: accesible de: http://web.ua.es/es/histrad/documentos/biografias/eusta- quio-barjau.pdf. 
d. José Luis Arántegui Tamayo. Doctor en Psicología y traductor del alemán, francés, italiano e inglés. Su tesis sobre el ambiente intelectual de la Viena finisecular, focalizado en la figura de Karl Kraus, parece haber determinado la elección de una parte de su traductografía. Ha vertido al español, entre otras muchas obras de contenido humanístico: Escritos de Karl Kraus, Madrid 1989 (varias reediciones); Actualidad de la filosofía. La idea de historia natural. De la relación entre sociología y psicología de Theodor W. Adorno Barcelona 1991, con varias reediciones; Cartas y anotaciones sobre la pintura de paisaje de Carl Gustav Carus, Madrid 1992; Sobre la dialéctica entre modernidad y posmodernidad: la crítica de la razón después de Adorno de Albrecht Wellmer, Madrid 1992; La lógica de la literatura de Käte Hamburger, Madrid 1995; Fin de siglo de Max Nordau, Jaén 1999; El caso Wagner de Friedrich Nietzsche, Madrid 2002; El paseante y su sombra también de Nietzsche, Madrid 2003; Canciones de viaje con quintas bohemias del compositor alemán Hans Werner Henze, Madrid 2004; Para una historia cultural de la sombra del historiador del arte Victor Stoichita, Madrid 2010. Sobre temas histórico-artísticos ha trasladado también obras de Paul Valéry (Eupalinos o El arquitecto. El alma y la danza; Piezas sobre arte) o de Stendhal o sobre Philipp Otto Runge o Joseph Beuys.

e. Miguel Ángel Vega Cernuda. ${ }^{27}$ Doctor en Filología alemana, catedrático de Traducción y traductor del alemán, latín, italiano, francés, danés e inglés. Traductor de obras literarias, entre otras, y muy especialmente textos clásicos y también sobre el cronotopo de su especialidad: la Viena finisecular y concretamente la obra de Arthur Schnitzler, aunque también tiene en su haber traducciones y ediciones críticas de Hugo von Hofmannsthal, Ödon von Horváth, Hugo Bettauer. La música, el arte, la literatura, la historia, la filosofía y el pensamiento abstracto conforman también su haber traductográfico, con, por ejemplo: Obras selectas de Friedrich Schlegel, Madrid 1983; Esbozo de Hölderlin, Schelling y Hegel, Hieronymus Complutensis 1, 1995, pp. 117-120; Vida del espíritu y tiempo de la polis. Hanna Arendt entre filosofía y política, Madrid 2001; Crítica de la razón cínica de Peter Sloterdijk, Madrid 2003 o Ira y tiempo: ensayo psicopolítico, Madrid 2010. En el campo de la teoría de la traducción, ha vertido al español textos de Cicerón, Plinio, san Agustín, Maimónides, Roger Bacon, Lutero, Thomas Moro, J. G. Schottelius, P. D. Huet, N. P. Ablancourt, Alexander Pope, J. J. Bodmer, G. Ventzky, J. Ch. Gottsched, J. J. Breitinger, Ch. Batteux, C. Goldoni, J. R. D’Alembert, Abbé Prévost, J. H. Herder, J. Delille, W. H. Gerstenberg, A. Burger, M. Wieland, Novalis, W. Schlegel, Mdme. de Staël, Wilhelm von Humboldt, J. W. von Goethe, H. Frere, J. Grimm, A. Schopenhauer, F. Nietzsche, L. Fulda, F. Rosenzweig, R. Pannwitz, V., Larbaud, H. Broch y H. Meschonnic en Textos clásicos de teoría de la traducción, Madrid

27 Para la ficha biográfica de E. Barjau véase: Juan Antonio ALBALADEJO, Miguel Ángel Vega [on-line], Alicante 2011. HISTRAD. Biografías de traductores, [consultado 29 diciembre de 2018]. Accesible de: http://web. ua.es/es/histrad/documentos/biografias/miguel-angel-vega.pdf; y el capítulo: "Producción bibliográfica de M. A. Vega", in: Pilar Martino Alba, Juan A. Albaladejo y Martha Pulido (eds.): Al humanista, traductor y maestro Miguel Ángel Vega Cernuda, Madrid 2013, pp. 17-37. 
1992. Por lo que respecta a textos de contenido histórico-artístico, no solamente ha abordado obras focalizadas en un arte plástico concreto, como la arquitectura de Los castillos del Loira, sino que su itinerancia vital ha dado como resultado una cosmovisión difícil de igualar para emprender la traducción geográfica, monumental y artística en la literatura de viajes, como pone de manifiesto la traslación al español de los Cuadros de viaje y Dioses en el exilio de Heinrich Heine, Madrid 2014, y otras muchas obras con amplio aparato crítico en la colección de literatura de viajes "Cómo nos vieron" de esta misma editorial.

\section{Conclusiones}

Al analizar el perfil biográfico y traductográfico de estos cinco traductores, de los que, por razones de espacio, tan solo presentamos una breve selección de su producción bibliográfica, salen a la luz una serie de características comunes: todos ellos eligieron en sus respectivas tesis doctorales temas que enlazaban claramente con la cultura de expresión alemana, como resultado de un conocimiento anterior del devenir cultural germánico y/o austriaco. Si bien cada uno de ellos inició su camino en un campo académico diferente (filosofía, filología, psicología, historia del arte y traducción) todos ellos han gozado de una profunda formación humanística e interdisciplinar que les ha permitido ser autores de textos en los que la capacidad heurística y el conocimiento de las ciencias humanísticas está fuera de toda duda. Además de ello, la revisión de los textos que han traducido al español demuestra que hay un amplio espectro de ideas y conceptos propios del pensamiento abstracto. Aunque en el campo histórico-artístico haya, obviamente, una amplia variedad de textos descriptivos, estos traductores tienen en su haber obras de teoría estética que, sin una buena formación filosófica, sería difícil de emprender. El camino parece haber sido el profundo conocimiento del contexto para, posteriormente, abordar el texto; en primer lugar, atendiendo al contenido, al sentido, y, posteriormente, a la forma.

A pesar de su variedad tipológica y de su innegable interés para la historia del arte, aunque no solo para esta disciplina académica, el hecho de que los textos de contenido histórico-artístico no tengan cabida en las ramas de la traducción especializada en los Estudios de Traducción, provoca que los traductores de este tipo de textos sean, por encima de cualquier otra consideración, humanistas que se han especializado en la traducción y no traductores que se hayan especializado en un determinado campo profesional. El que la formación humanística haya quedado relegada a un segundo plano en los estudios de traducción tiene consecuencias laborales negativas.

El papel que el traductor desempeña en la sociedad va más allá del profesional que desarrolla su labor con rigor; es un mediador lingüístico y cultural que en el campo de la traducción humanística contribuye a que avance el conocimiento y, consecuentemente, a que se amplíe el polisistema cultural al que vierte el pensamiento y la reflexión de la cultura de la que traduce.

El trabajo de los traductores mencionados en este artículo no produce como único resultado el que se nos facilite a los lectores interesados un más fácil acceso a textos de contenido histórico-artístico, sino que es al mismo tiempo fuente documental para la investigación en ciencias humanísticas. 
Su traductografía demuestra con creces que en el campo de la traducción es necesaria la investigación, aunque en ciertos ámbitos académicos este hecho se desconozca. Los traductores constantemente deben probar que el componente investigador es inherente al proceso traductor y que, consecuentemente, no es posible la traducción de calidad sin investigación ni sin una exhaustiva revisión documental previa.

Tras la revisión bibliográfica efectuada y el estudio sobre los tipos de texto y su contenido, su traducción y su recepción, volvemos a la introducción que hacíamos del tema y a una de las cuestiones que nos planteábamos, a saber: la ausencia de este campo temático entre los focos de interés de la traducción especializada. Al respecto concluímos que la falta de formación humanística o, al menos, una apenas esbozada formación integral en los estudios de traducción es una de las razones fundamentales de la dificultad de los graduados en traducción para abordar textos de contenido histórico-artístico, sea cual sea su temática, asunto este de no fácil solución, toda vez que en los planteamientos curriculares prima lo económico sobre lo humanístico, lo tangible frente al fomento de la capacidad heurística y de la visión crítica, lo fácil y aparentemente rentable frente a lo aparentemente difícil pero de proyección personal y profesional a largo plazo.

La inversión en productos culturales que fomenten el afán por saber, el avance del conocimiento no solo entre los especialistas, sino también entre el público lector, espectador y observador que desee ampliar su bagaje cultural y la conformación de un polisistema cultural de calidad supone hoy día nadar contracorriente. Precisamente por ello, desde estas páginas expresamos nuestro más profundo y sincero agradecimiento a todos esos traductores humanistas, especialistas en áreas de conocimiento que exigen reflexión y amor por la cosa en sí, a esos sanadores del alma de los receptores, porque sin su esfuerzo y su dedicación a la causa translatoria y traductográfica estaríamos culturalmente más necesitados de auxilio y tratamiento.

Este artículo abre nuevas líneas de investigación sobre los actores de la traducción de textos histórico-artísticos, así como sobre su recepción, asuntos que abordaremos en posteriores artículos. Las características y dificultades de la amplia paleta de textos de contenido histórico-artístico han sido abordados con anterioridad por quien suscribe. Precisamente, al tratarse de textos plurigenéricos y diversos desde el punto de vista formal, conforman un corpus de gran interés para proseguir investigando en este ámbito.

(Escrito en español por la autora) 


\section{BIBLIOGRAFÍA}

ALBALADEJO, Juan Antonio, Miguel Ángel Vega [on-line], Alicante: Universidad de Alicante, 2011. HISTRAD. Biografías de traductores. Accesible de: http://web. ua.es/es/histrad/documentos/biografias/miguel-angel-vega.pdf, [consultado 29 diciembre de 2018].

ALBALADEJO, Juan Antonio, Eustaquio Barjau [on-line], Alicante: Universidad de Alicante, 2012. HISTRAD.Biografías de traductores.Accesible de: http://web.ua.es/es/histrad/documentos/biografias /eustaquio-barjau.pdf, [consultado 27 de diciembre de 2018].

BORRÁS, Gonzalo, Historia del arte y Patrimonio Cultural: una revisión crítica, Zaragoza: Prensas Universitarias de Zaragoza, col. Paraninfo, 2012.

BÜHLER, Karl, Sprachtheorie. Die Darstellungsfunktion der Sprache, Jena: G. Fischer, 1934.

BUONARROTI, Miguel Ángel, Sonetos completos [edición bilingüe de Luis Antonio de Villena], Madrid: Cátedra, col. Letras Universales, 1987.

CARUS, Carl Gustav, Cartas y anotaciones sobre la pintura de paisaje [traducción de José Luis Arántegui], Madrid: Visor, 1992.

HEINE, Heinrich, Cuadros de Viaje. Los dioses en el exilio [estudio introductorio, traducción y notas de Miguel Ángel Vega Cernuda y Elena Serrano Bertos], Madrid: Ed. Cátedra, 2015.

HELLWIG, Karin, La literatura artística española del siglo XVII [trad. de Jesús Espino Nuño], Madrid: Visor, col. "La balsa de la Medusa", 1999.

HORACIO, Arte poética [edición bilingüe, introducción y notas de Juan Gil], Madrid: Dykinson, col. "Clásicos Dykinson", 2010.

LESSING, Gotthold Ephraim, Laocoonte [traducción de Eustaquio Barjau], Madrid: Editora Nacional, 1977; y Madrid: Tecnos, 1990.

MARTINO ALBA, Pilar, La autobiografía artística como problema de traducción, Alicante: Universidad de Alicante, 2016.

MARTINO ALBA, Pilar, "La formación humanística ante la traducción especializada", in: Antonio Bueno y Miguel Ángel Vega (eds.), Traducción y Humanismo, Bruselas: Éditions du Hazard, 2013, pp. 297-312.

MARTINO ALBA, Pilar, "La traducción de textos histórico-artísticos", Philologia Hispalensis XIX/2, 2005, pp. 149-163.

REISS, Katharina, "Type, Kind and Individuality of Text: Decision Making in Translation", Poetics Today 2/4, (=Translation Theory and Intercultural Relations. Summer-Autumn 1981), 1981, pp. 121-131.

REJÓN DE SILVA, Antonio, El tratado de la pintura por Leonardo da Vinci y los tres libros que sobre el mismo arte escribió León Bautista Alberti, Madrid: Imprenta Real, 1784.

VEGA, Miguel Ángel, Miguel Ángel VEGA: Textos clásicos de teoría de la traducción, Madrid: Cátedra, 1994 [2004].

VVAA, Historiografía artística española de los siglos XIX y XX, Madrid: CSIC, 1995.

ZALAMA, Miguel Ángel, "Un ejemplar de Cuatro libros sobre las proporciones humanas de Durero en la Biblioteca de Santa Cruz de Valladolid", Boletín del Seminario de Estudios de Arte y Arqueología 68, 2002, pp. 191-198.

\section{Breve información sobre la autora}

\section{Correo electrónico: pilar.martino@urjc.es}

Doctora en Historia del Arte por la Universidad Complutense de Madrid y Doctora en Traducción e Interpretación por la Universidad de Alicante. Profesora Titular de Universidad, Universidad Rey Juan Carlos, Madrid, y del Máster de Traducción de la Universidad Ricardo Palma, Lima. Ha sido docente de Teoría y Práctica de la Traducción, de Metodología de la Traducción, y, ocasionalmente, de Historia de la Traducción en el Instituto Universitario de Lenguas Modernas y Traductores de la Universidad Complutense durante tres lustros. Visiting Professor en la Universidad 
de Münster, becada por el DAAD, y en la Hochschule Magdeburg-Stendal. Ha sido también becada por el Istituto Italiano di Cultura (Laboratorio Internazionale della Comunicazione, Università d'Udine e Università Cattolica di Milano). Autora de medio centenar de artículos y editora y/o coeditora de varias monografías en torno a la traducción; ejerce la traducción literaria. Es miembro cofundador del grupo de investigación MHISTRAD/TRADEC. Ha participado en varios proyectos de investigación I+D sobre traducción de textos misioneros. Entres sus áreas de interés pertenecen: Historia del Arte, Traducción e Interpretación, Traducción literaria, Filología alemana. 